\title{
Superheat Control Of Evaporator Outlet In Air Conditioning
}

\author{
Na $\mathrm{Li}^{*}$, Xiangdong Wang \\ *School of Information Science and Engineering, Shenyang University of Technology, Shenyang, 110870, China
}

Keywords: Superheat; Evaporator; Model Uncertainty; Robust Control

\begin{abstract}
In order to control effectively the superheat, improve the utilization of evaporator and make the refrigeration system run stably, this paper sets up a dynamic model of the mobile phase interface first, and linearizes the model in operating point to obtain a five-order liner equation. Secondly, the modeling process and linear process for the model will cause a certain error for the model, so in order to track the superheat, this paper adopts the robust control method based on the improved quadratic performance index to design the output tracking controller. Finally, this paper also presents the simulation analysis with Matlab as a tool to verify that the designed controller can achieve the satisfactory control effect on superheat tracking control.
\end{abstract}

\section{Introduction}

Environmental pollution and energy shortage, etc. have attracted more and more attention all over the world. Under such environment, the main energy-consuming part of the airconditioning system is the refrigerating system. In the control of refrigeration system, the control of evaporator superheat is important, which not only directly affects the reliability and operation efficiency of the system, but also links with various control in the refrigeration system control or realize them on its basis. The liquid supply volume of evaporator is controlled and the evaporator superheat is adjusted via controlling refrigerant mass flow rate passing expansion valve, so as to ensure the capacity utilization of evaporator. Therefore, the research on mechanism modeling and control algorithm for evaporator superheat control system has become a research focus in the field of air conditioning.

The research at home and abroad on evaporator modeling and superheat control has been conducted for decades. He XiangDong et al. established the multivariable feedback control mathematical model of refrigeration system, which was a mathematical model used for control; Bai Ziyun and Chen Zhijiu adopted the self-tuning adaptive algorithm to identify the model according to the superheat of evaporator and experimental value of valve opening. In terms of the control algorithm, the most widely-used one is PID or PI regulation, which is relatively simple and mature, but the common problem is that the parameter selection and adjustment are inconvenient; due to the complexity and nonlinear of the control object of evaporator, Yin Youjun et al. applied the fuzzy control to evaporator superheat control with a satisfactory effect; Zhu Ruiqi et al. introduced the genetic algorithm based on the dynamic simulation to optimize the membership function of the fuzzy control of evaporator superheat, and provided the optimization scheme.

This paper considers the internal flow pattern of evaporator when establish the dynamic model of evaporator, adopts the sub-regional lumped parameter model for the evaporator and conducts the linear processing for the model in system operation condition. There are some inevitable errors in the accuracy of model compared with the actual object model in the process of modeling, combined with the uncertainty of model caused by simplifying the model according to the need of designing controller, it is needed to fully consider the influence of the uncertainty of control system in the actual design process, study the robustness of system and design the controller with a certain robust control performance, so as to achieve the purpose of superheat control. This paper adopts the robust output tracking method based on improved quadratic performance index to design the robust controller ${ }^{[1]}$, so as to make the refrigerant superheat at evaporator outlet reach the preset value.

\section{Establishment of model}

\subsection{One-dimensional evaporator flow heat transfer equation}

The evaporator is divided into two areas according to the state of refrigerant along the tube: two-phase region and overheated region. Based on the mass conservation, momentum conservation and energy conservation equation of fluid mechanics, the flow heat transfer equation can be described as a group of complex nonlinear partial differential equations ${ }^{[2]}$. In order to simplify these equations into tractable mathematical version, the following assumptions are set:

1) Evaporator is the long thin-wall horizontal tube;

2) The refrigerating fluid flows in the evaporator tube in one dimension;

3) The axial heat transfer and the influence of gaseous impurity on heat transfer are ignored.

Based on the above assumptions, the evaporator model can be described by the following set of equations ${ }^{[3]}$ as formulas (1), (2), (3):

Mass balance: 


$$
\frac{\partial \rho}{\partial t}+\frac{\partial(\rho u)}{\partial z}=0
$$

Momentum conservation:

$$
\frac{\partial(\rho u)}{\partial t}+\frac{\partial\left(\rho u^{2}+P\right)}{\partial z}=-\frac{4}{D_{i}} \mu \frac{1}{2} \rho u^{2}
$$

Energy conservation:

$$
\frac{\partial(\rho h-P)}{\partial t}+\frac{\partial \rho u h}{\partial z}=\frac{4}{D_{i}} \alpha_{i}\left(T_{w}-T_{r}\right)
$$

Wall energy conservation:

$$
\left(C_{w} \rho_{w} A_{w}\right) \cdot \frac{d T_{w}}{d t}=\alpha_{i} \pi D_{i}\left(T_{r}-T_{w}\right)+\alpha_{o} \pi D_{o}\left(T_{a}-T_{w}\right)
$$

In the formulas, $\mathrm{u}$ indicates the flow velocity of refrigerant along the pipe; $\mathrm{P}$ indicates the pressure of refrigerant in evaporator tube; $\rho$ indicates the density of refrigerant; $D$ indicates the diameter of pipe; $h$ indicates the enthalpy of refrigerant; $\mu$ indicates the dynamic viscosity coefficient of refrigerant; $\alpha_{i}$ and $\alpha_{0}$ indicate the unit coefficient of heat transfer between refrigerant and pipe wall and coefficient of outer heat transfer; $\left(\mathrm{C}_{\mathrm{w}} \rho_{\mathrm{w}} \mathrm{A}_{\mathrm{w}}\right)$ indicates the heat capacity of evaporator wall unit length.

In order to simplify the model and ignore the influence of pressure drop inside, it is thought that the internal pressure of evaporator is uniform along the tube and the temperature of refrigerant in two-phase region remains constant, so the momentum conservation equation can be omitted.

\subsection{Modeling}

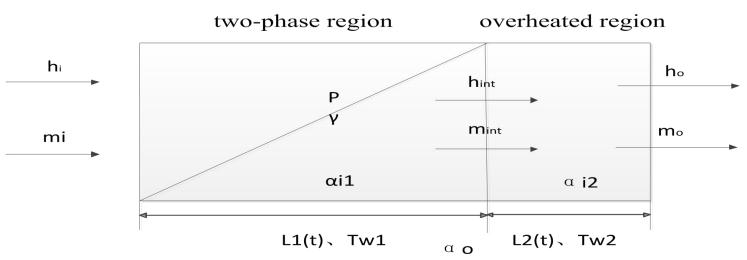

Fig 1. Schematic diagram of evaporator model.

In the two-phase region, the refrigerant in the tube is in the gas and liquid states, as shown in figure 1, and in order to get lumped parameter, the theory of average void fraction is adopted; in other words, the average void fraction in twophase region of heat exchanger remains the same. So we can express the proportion of liquid and gas phase in two-phase region in different times as $\gamma$, namely the average void fraction. Leibnitz's formula is shown as formula (5):

$$
\int_{z_{1}(t)}^{z_{2}(t)} \frac{\partial f(z, t)}{\partial t} d z=\frac{d}{d t}\left[\int_{z_{1}(t)}^{z_{2}(t)} f(z, t) d z\right]-f\left(z_{2}(t), t\right) \frac{d\left(z_{2}(t)\right)}{d t}+f\left(z_{1}(t), t\right) \frac{d\left(z_{1}(t)\right)}{d t}
$$

Applying the formula, the integral is conducted from $\mathrm{z}=0$ to $\mathrm{z}=\mathrm{L}_{1}(\mathrm{t})$ for one-dimensional heat transfer equation of fluid mechanics along the tube, and the moving boundary model in two-phase region ${ }^{[4]}$ is obtained as formulas (6), (7) and (8):

Mass conservation:

$$
A L_{1}\left[\gamma \cdot \frac{d \rho_{g}}{d P}+(1-\gamma) \frac{d \rho_{l}}{d P}\right] \cdot \frac{d P}{d t}+A(1-\gamma)\left(\rho_{l}-\rho_{g}\right) \cdot \frac{d L_{1}}{d t}=m_{i}-m_{\mathrm{int}}
$$

Energy conservation:

$$
\begin{gathered}
A L_{1}\left[\frac{d\left(\rho_{l} h_{l}\right)}{d t}(1-\gamma)+\frac{d\left(\rho_{g} h_{g}\right)}{d t} \cdot \gamma-\frac{d P}{d t}\right]+A(1-\gamma)\left(\rho_{l} h_{l}-\rho_{g} h_{g}\right) \frac{d L_{1}}{d t} \\
=m_{i} h_{i}-m_{\mathrm{int}} h_{\mathrm{int}}+\alpha_{i 1} \pi D_{i} L_{1}\left(T_{w 1}-T_{r 1}\right)
\end{gathered}
$$

Tube wall energy conservation:

$$
A L_{1}\left[\gamma \frac{d \rho_{g}}{d P}+(1-\gamma) \frac{d \rho_{l}}{d P}\right] \cdot \frac{d P}{d t}+A(1-\gamma)\left(\rho_{l}-\rho_{g}\right) \frac{d L_{1}}{d t}=m_{i}-m_{\mathrm{int}}
$$

In overheated region, the same method is adopted. The integral is conducted using Leibnitz's formula from $z=L_{1}(t)$ to $\mathrm{z}=\left(\mathrm{L}_{1}+\mathrm{L}_{2}\right)(\mathrm{t})$ for one-dimensional heat transfer equation of fluid mechanics along the tube, and the moving boundary model in overheated region is obtained as formulas (9), (10) and (11):

Mass conservation:

$$
A L_{2} \frac{d \rho_{2}}{d t}+A\left(\rho_{g}-\rho_{2}\right) \frac{d L_{1}}{d t}=m_{\text {int }}-m_{o}
$$

Energy conservation:

$$
\begin{array}{r}
A L_{2}\left(\rho_{2} \frac{d h_{2}}{d t}+h_{2} \frac{d \rho_{2}}{d t}-\frac{d P}{d t}\right)+A\left(\rho_{g} h_{g}-\rho_{2} h_{2}\right) \frac{d L_{1}}{d t} \\
=m_{\mathrm{int}} h_{\mathrm{int}}-m_{o} h_{o}+\alpha_{i 2} \pi D_{i} L_{2}\left(T_{w 2}-T_{r 2}\right)
\end{array}
$$

Tube wall energy conservation:

$$
\left(C_{w} \rho_{w} A_{w}\right)\left(\frac{d T_{w 2}}{d t}+\frac{T_{w 1}-T_{w 2}}{L_{2}} \frac{d L_{1}}{d t}\right)=\alpha_{i 2} \pi D_{i}\left(T_{r 2}-T_{w 2}\right)+\alpha_{o} \pi D_{o}\left(T_{a}-T_{w 2}\right)
$$

In the formula , $\mathrm{L}_{1}$ and $\mathrm{L}_{2}$ indicate the length of two-phase region and overheated region, $\mathrm{m} ; \rho_{\mathrm{g}}$ and $\rho_{\mathrm{l}}$ are the density of saturated gas and saturated of refrigerant, $\mathrm{kg} / \mathrm{m}^{3} ; \mathrm{h}_{\mathrm{g}}$ and $\mathrm{h}_{\mathrm{l}}$ are the specific enthalpy of saturated gas and saturated liquid of refrigerant, $\mathrm{kj} / \mathrm{kg} ; \mathrm{h}_{\mathrm{i}}, \mathrm{h}_{\mathrm{o}}, \mathrm{h}_{\mathrm{int}}$ and $\mathrm{h}_{2}$ are respectively the average specific enthalpy of evaporator inlet, outlet refrigerant and refrigerant between in two-phase region and overheated region and refrigerant in overheated region, $\mathrm{kj} / \mathrm{kg} ; \mathrm{m}_{\mathrm{i}}$, mint and $m_{0}$ are the mass flow rate of refrigerants in the inlet of evaporator, between the two-phase region and overheated and evaporator outlet, $\mathrm{kg} / \mathrm{s} ; \mathrm{T}_{\mathrm{rl}}, \mathrm{T}_{\mathrm{w} 1}$ and $\mathrm{T}_{\mathrm{a}}$ are the average temperature of refrigerant in two-phase region, tube wall and the average temperature at the outer wall; $\rho_{2}$ indicates the average density of refrigerant in overheated zone, $\rho_{2}=\rho\left(\rho_{\mathrm{e}}, \mathrm{h}_{2}\right)$, $\mathrm{kg} / \mathrm{m}^{3} ; \mathrm{T}_{\mathrm{r} 2}$ and $\mathrm{T}_{\mathrm{w} 2}$ are the temperature of refrigerants in overheated region and tube wall, $\mathrm{K}$.

Under the above six simultaneous equations of evaporator, the intermediate variables are eliminated. The state variable of evaporator is $\mathrm{x}=\left[\begin{array}{lll}\mathrm{L}_{1} & \mathrm{P} \mathrm{h}_{\mathrm{o}} & \mathrm{T}_{\mathrm{w} 1} \mathrm{~T}_{\mathrm{w} 2}\end{array}\right]^{\mathrm{T}}$, and other variables in the equations can be used as the input, namely the control variable $\mathrm{u}=\left[\begin{array}{llll}\mathrm{m}_{\mathrm{i}} & \mathrm{h}_{\mathrm{i}} & \mathrm{m}_{\mathrm{o}}\end{array}\right]^{\mathrm{T}}$, and then the evaporator dynamic model is obtained as formula (12):

$$
D(x) \cdot x=f(x, u)
$$

Where,

$$
D(x)=\left[\begin{array}{ccccc}
d_{11} & d_{12} & 0 & 0 & 0 \\
d_{21} & d_{22} & d_{23} & 0 & 0 \\
d_{31} & d_{32} & d_{33} & 0 & 0 \\
0 & 0 & 0 & d_{44} & 0 \\
d_{51} & 0 & 0 & 0 & d_{55}
\end{array}\right] f(x, u)=\left[\begin{array}{c}
m_{i} h_{i}-m_{i} h_{g}+\alpha_{i 1} \pi D_{i} L_{1}\left(T_{w 1}-T_{r 1}\right) \\
m_{o} h_{g}-m_{o} h_{o}+\alpha_{i 1} \pi D_{i} L_{2}\left(T_{w 2}-T_{r 2}\right) \\
m_{i}-m_{o} \\
\alpha_{i 1} \pi D_{i}\left(T_{r 1}-T_{w 1}\right)+\alpha_{o} \pi D_{o}\left(T_{a}-T_{w w}\right) \\
\alpha_{i 2} \pi D_{i}\left(T_{r 2}-T_{w 2}\right)+\alpha_{o} \pi D_{o}\left(T_{a}-T_{w 2}\right)
\end{array}\right]
$$

The coefficient of matrix $\mathrm{D}(\mathrm{x})$ in the formula (12) is: $d_{11}=-A(1-\gamma) \rho_{l}\left(h_{g}-h_{l}\right)$ 


$$
\begin{aligned}
& d_{12}=A L_{1}\left[-(1-\gamma) \frac{d \rho_{l}\left(h_{g}-h_{l}\right)}{d t}+\rho_{l} \frac{d h_{g}}{d P}-1\right], d_{21}=-\frac{1}{2} A\left(h_{o}-h_{g}\right) \\
& d_{22}=A L_{2}\left[\frac{1}{2} \rho_{2} \frac{d h_{g}}{d P}+\frac{1}{2}\left(h_{o}-h_{g}\right) \frac{\partial \rho_{2}}{\partial P}-1\right], d_{23}=A L_{2}\left[\frac{1}{2} \rho_{2}+\frac{h_{o}-h_{g}}{2} \frac{\partial \rho_{2}}{\partial h_{o}}\right] \\
& d_{31}=A\left(\gamma \rho_{g}+(1-\gamma) \rho_{l}-\rho_{2}\right), d_{32}=A L_{1} \frac{d \rho_{l}}{d P}+A L_{2} \frac{\partial \rho_{2}}{\partial P} \\
& d_{33}=A L_{2} \frac{\partial \rho_{2}}{\partial h_{o}}, d_{44}=d_{55}=C_{w} \rho_{w} A_{w}, d_{51}=d_{44} \cdot \frac{T_{w 1}-T_{w 2}}{L_{2}}
\end{aligned}
$$

\subsection{Linearization}

According to the linear theory, linearization is performed at the operating point of evaporator $\mathrm{X}_{0}=\left[\begin{array}{lll}14.4 & 636793 & 416.022\end{array}\right.$ $282.15 \quad 287.15]^{\mathrm{T}}$ and $\mathrm{u}_{0}=\left[\begin{array}{lllll}0.011151 & 318.22 & 0.0111 & 0.0077\end{array}\right]^{\mathrm{T}}$, and the linear model below can be obtained as formula (13):

$$
\dot{X}=A \cdot \Delta X+B \cdot \Delta u
$$

The output variable of system is set as $\mathrm{y}=\left[\mathrm{T}_{\mathrm{sh}}\right]$, and it can be known according to the definition of superheat that the superheat is equal to the difference between temperature corresponding to the pressure at the evaporator outlet and temperature of tube wall at the overheat region, namely $\mathrm{T}_{\mathrm{sh}}=-$ $0.000443 \mathrm{P}+\mathrm{T}_{\mathrm{w} 2}$, and we get the system output equation as formula (14):

$$
y=C \cdot X
$$

It can be seen that the state equation after linearization as formula (15).

$$
\left\{\begin{array}{c}
\dot{X}=A \cdot \Delta X+B \cdot \Delta u \\
y=C \cdot X
\end{array}\right.
$$

The fitting parameters used in the process of modeling and model parameter calculation $^{[5]}$ can make the model have certain errors and uncertainty, so $\Delta \mathrm{A}$ and $\Delta \mathrm{B}$ are the uncertainty of $\mathrm{A}$ and $\mathrm{B}$ matrix satisfying the matching conditions, $\Delta \mathrm{A}=\mathrm{BD}, \Delta \mathrm{B}=\mathrm{BE}$, and $\Delta \mathrm{X}$ and $\Delta \mathrm{u}$ are spread as formular (16).

$$
\left\{\begin{array}{c}
\dot{X}=(A+\Delta A) \cdot X+(B+\Delta B) \cdot u+l \\
y=C \cdot X
\end{array}\right.
$$

The above system model (16) is transformed into the standard linear uncertain system model; first, consider transforming the constant $\mathrm{l}$. The control input is set as $\mathrm{u}=\mathrm{u}_{1}+\mathrm{u}_{2}$, the $\mathrm{u}_{1}$ is the variable to be solved, and $\mathrm{u}_{2}$ realizes $(\Delta \mathrm{B}+\mathrm{B}) \mathrm{u}_{2}+\mathrm{l}=0$, and the above model (16) is transformed into the following equation as (17):

$$
\left\{\begin{array}{c}
\dot{X}=(A+\Delta A) \cdot X(t)+(B+\Delta B) \cdot u(t) \\
y(t)=C \cdot X(t)
\end{array}\right.
$$

Here,

$$
\mathrm{A}=\left[\begin{array}{ccccc}
-0.0178 & 6.7896 \cdot 10^{-6} & -0.0146 & -0.3906 & 0.0300 \\
-47.7884 & 0.1118 & 31.0133 & -1.6326 \cdot 10^{3} & -63.4647 \\
-6.8757 & 0.0019 & -6.2220 & -146.6332 & 12.7325 \\
0 & 6.4839 \cdot 10^{-4} & 0 & -14.8957 & 0 \\
-0.0247 & 5.3917 \cdot 10^{-4} & -0.0059 & -0.5426 & -3.3418
\end{array}\right]
$$

$$
\begin{aligned}
& \mathrm{B}=\left[\begin{array}{cccc}
186.2667 & -0.0043 & -160.9058 & 0 \\
-1.7389 \cdot 10^{5} & -18.0851 & 3.4077 \cdot 10^{5} & 0 \\
-1.5126 \cdot 10^{4} & -1.6243 & 2.4166 \cdot 10^{4} & -5.0558 \cdot 10^{-15} \\
0 & 0 & 0 & 0.3427 \\
258.7038 & -0.0060 & -223.4803 & -0.2523
\end{array}\right] \\
& C=\left[\begin{array}{llccc}
0 & -0.000443 & 0 & 0 & 1
\end{array}\right] \\
& D=\left[\begin{array}{lllll}
0 & 1 & 0 & 0 & 0 \\
0 & 0 & 1 & 0 & 0 \\
0 & 0 & 0 & 1 & 0 \\
0 & 0 & 0 & 0 & 1
\end{array}\right] \quad \mathrm{E}=\left[\begin{array}{cccc}
0 & 0.1 & 0 & 0 \\
0 & 0 & 0.2 & 0 \\
0 & 0 & 0 & 0.1 \\
0 & 0 & 0 & 0
\end{array}\right]
\end{aligned}
$$

\section{Robust controller design}

Using robust control method to design the controller, which satisfies the matching condition by considering its uncertainties $\Delta \mathrm{A}=\mathrm{BD}, \Delta \mathrm{B}=\mathrm{BE}, \sup \|\mathrm{D}\|=\delta, \sup \|\mathrm{E}\|=\beta$, and $\mathrm{E}^{\mathrm{T}}+\mathrm{E}+\mathrm{I}_{\mathrm{m}}$ is positive semidefinite, here $\mathrm{I}_{\mathrm{m}}$ means the $\mathrm{m}$ dimensional identity matrix. First, we construct the augmented system equation ${ }^{[6]}$ as (18):

$$
\left\{\begin{array}{c}
X(t)=(A+\Delta A) \cdot X(t)+(B+\Delta B) \cdot u(t) \\
q(t)=C \cdot X(t)-y_{r}
\end{array}\right.
$$

Where $\mathrm{q}(\mathrm{t})$ is an auxiliary state and $\mathrm{y}_{\mathrm{r}}(\mathrm{t})$ is the desired constant reference output. Rewriting (18) into an augmented state equation as following (19):

$$
z(t)=\left(A_{z}+\Delta A_{z}\right) \cdot z(t)+\left(B+\Delta B_{z}\right) \cdot u(t)+\xi
$$

Where, $\Delta \mathrm{A}_{\mathrm{z}}=\mathrm{B}_{\mathrm{z}} \mathrm{D}_{\mathrm{z}}, \Delta \mathrm{B}_{\mathrm{z}}=\mathrm{B}_{\mathrm{z}} \mathrm{E}_{\mathrm{z}}, \mathrm{Dz}=\left[\mathrm{D}_{\mathrm{z}} 0\right], \mathrm{E}_{\mathrm{z}}=\mathrm{E}$

$$
\begin{aligned}
& z(t)=\left[\begin{array}{c}
X(t) \\
q(t)
\end{array}\right], A_{z}=\left[\begin{array}{ll}
A & 0 \\
C & 0
\end{array}\right], \Delta A_{z}=\left[\begin{array}{cc}
\Delta A & 0 \\
0 & 0
\end{array}\right], B_{z}=\left[\begin{array}{c}
B \\
0
\end{array}\right] \\
& \Delta B_{z}=\left[\begin{array}{c}
\Delta B \\
0
\end{array}\right], \xi=\left[\begin{array}{c}
0 \\
-y_{r}
\end{array}\right]
\end{aligned}
$$

For the aforementioned augmented equation, take the optimal index with a prescribed degree of stability, as shown in the following equation (20):

$$
J=\int_{0}^{\infty} \exp (2 \varepsilon t)\left[\zeta z(t)^{T} z(t)+\rho u(t)^{T} u(t)\right] d t
$$

Where $\zeta$ and $\rho$ are positive numbers, and where the parameter $\varepsilon$ is a positive number denoting the prescribed degree of stability. By conventional optimization techniques, the optimal solution is $u(t)=-\rho^{-1} B_{z}^{T} P z(t)=-k z(t)$, where $P$ is the steady-state solution of the following Riccati equation (21):

$$
\left(A_{z}+\varepsilon I_{z}\right)^{T} P+P\left(A_{z}+\varepsilon I_{z}\right)-\rho^{-1} P B_{z} B_{z}^{T} P+\zeta I_{z}=0
$$

Here $I_{z}$ the $(n+r)$-dimensional identity matrix. In order to accommodate the intrinsic uncertainties, the resultant input ${ }^{[6]}$ is modified as the following equation (22):

$$
u(t)^{*}=-K \cdot z(t)=-(1+\alpha) k \cdot z(t)
$$

Where $\alpha \geq 0$ is the adapting factor to be determined, and $\alpha=\rho \delta^{2} / \zeta$. 


\section{Simulation study}

This part is the simulation and verification for the above controller design, part of the parameters of the evaporator as shown in table I:

\begin{tabular}{c|c}
\hline \hline Inner Tube Diameter & $0.0063 \mathrm{~m}$ \\
\hline Outer Tube Diameter & $0.0065 \mathrm{~m}$ \\
\hline Evaporator Length & $18 \mathrm{~m}$ \\
\hline Wall Thermal Capacity & $0.385 \mathrm{kj} /(\mathrm{kg} * \mathrm{~K})$ \\
\hline Wall Specific Density & $8960 \mathrm{~kg} / \mathrm{m}^{3}$ \\
\hline Inlet Enthalpy & $318.22 \mathrm{kj} / \mathrm{kg}$ \\
\hline Mass Flow Inlet & $0.0112 \mathrm{~kg} / \mathrm{s}$ \\
\hline Outside Heat Transfer Coefficient & $0.593 \mathrm{kw} /\left(\mathrm{m}^{2 *} \mathrm{~K}\right)$ \\
\hline $\begin{array}{c}\text { Heat Transfer Coefficient in Two- } \\
\text { phase Region }\end{array}$ & $3.520 \mathrm{kw} /\left(\mathrm{m}^{2 *} \mathrm{~K}\right)$ \\
\hline $\begin{array}{c}\text { Heat Transfer Coefficient in } \\
\text { Overheated Region }\end{array}$ & $0.327 \mathrm{kw} /\left(\mathrm{m}^{2 *} \mathrm{~K}\right)$ \\
\hline \hline
\end{tabular}

Table I: Part of the Parameters of the Evaporator

Set system's stable operating point, the length of two-phase region $\left(\mathrm{L}_{1}\right)$ is $14.4 \mathrm{~m}$, the stable superheat $\left(\mathrm{T}_{\mathrm{sh}}\right)$ is $5^{\circ} \mathrm{C}$, the temperature of tube wall of the two-phase region $\left(\mathrm{T}_{\mathrm{w} 1}\right)$ is $282.15 \mathrm{~K}$. Some of the intermediate parameters in the model can be calculated according to some calculation methods of the thermal physical properties of refrigerant, and the dynamic model of the system is obtained, and the matrix $\mathrm{P}$ and matrix $\mathrm{K}$ are obtained according to the method mentioned above:

$$
\begin{aligned}
\mathrm{P} & =\left[\begin{array}{ccccccc}
3555290 & -0.1942 & 3.3372 & -142691 & -1912844 & -7119162 \\
-0.1942 & 3.656910^{4} & -0.0062 & 0.0258 & 0.0212 & 0.1778 \\
3.3372 & -0.0062 & 0.1059 & -0.4427 & -0.3650 & -3.0558 \\
-14.2691 & 0.0258 & -0.4427 & 1.9495 & 1.6944 & 13.5701 \\
-191.2844 & 0.0212 & -0.3650 & 1.6944 & 130.6396 & 453.3180 \\
-711.9162 & 0.1778 & -3.0558 & 13.5701 & 453.3180 & 1618.3
\end{array}\right] \\
\mathrm{K} & =\left[\begin{array}{ccccccc}
27.6107 & -0.8229 & -1.0302 & -3.3612 & -4.1481 & -27.6275 \\
-2.2896 & 0.0041 & -0.0725 & 0.3043 & 0.2476 & 2.0893 \\
11.7693 & 1.8236 & -0.4337 & -1.4185 & -1.8599 & -11.9813 \\
43.3710 & 0.0035 & -0.0596 & 0.2406 & -323297 & -109.7217
\end{array}\right]
\end{aligned}
$$

The preset setting values are $4^{\circ} \mathrm{C}$ and $5^{\circ} \mathrm{C}$ when the system is simulated:

When the pressure is $636.793 \mathrm{kpa}$, the presetting superheat is $4.5^{\circ} \mathrm{C}$, it can be seen from the figure below the superheat of evaporator outlet from $5^{\circ} \mathrm{C}$ to gradually achieve the preset setting value of $4.5^{\circ} \mathrm{C}$, and then tend to stable, as in Fig 2:

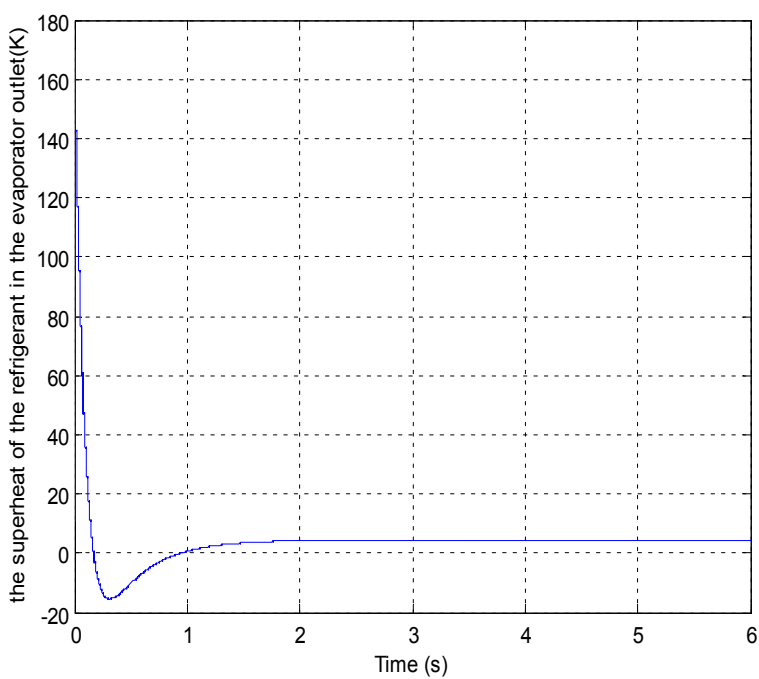

Fig 2. Superheat curve of refrigerant in evaporator outlet.

When the pressure is $650.080 \mathrm{kpa}$, the presetting superheat is $4^{\circ} \mathrm{C}$, from the figure below it can be seen that the superheat at the evaporator outlet from $5^{\circ} \mathrm{C}$ to gradually reached the preset setting value of $4^{\circ} \mathrm{C}$, and then tend to stable, as in Fig 3:

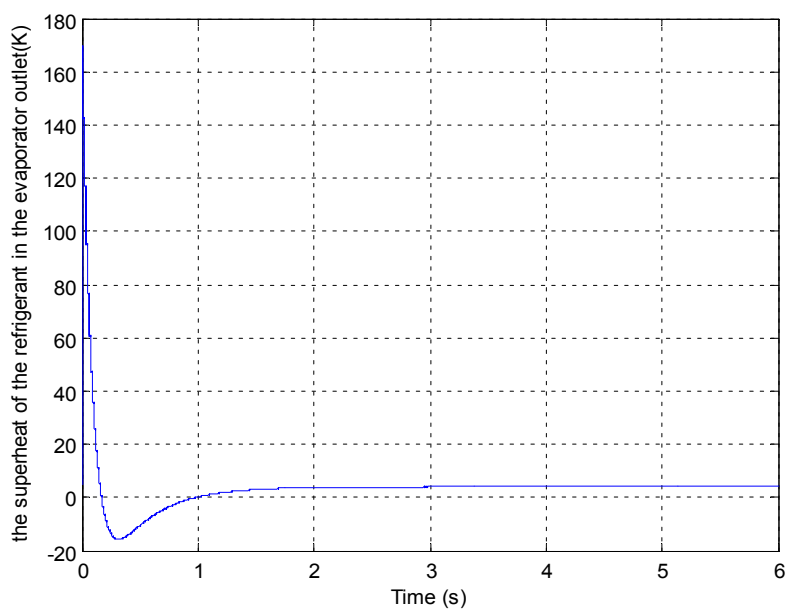

Fig 3. Superheat curve of refrigerant in evaporator outlet.

Simulation results for two cases show that, the designed controller can make the superheat of refrigerant in evaporator outlet reach the preset value quickly, and the system remain stable, and it is shown that the designed controller is reasonable and effective, and has strong robustness.

\section{Conclusions}

First of all, this paper conducts the evaporator modeling, divides the refrigerants into two different areas according to its state in air conditioning evaporator, and the equations are built in each region using the method of lumped parameter model. Then the equations in the two areas are synthesized to get 5-order nonlinear model. Then the model receives the linear processing and analyzed combined with the robust characteristics to get the 5-order uncertain linear system state equation. Second a robust tracking controller is designed 
based on the improved optimal performance index, which is used to determine the uncertain linear model, so as to make the superheat of the refrigerant in the evaporator outlet reach the preset value. Finally, Matlab software is used for simulation verification. The simulation results show that the robust controller designed can make the superheat of refrigerant in evaporator outlet reach the preset value and meet the control law, and indicate that the design method of state feedback controller is effective with strong adaptability and robustness, which can effectively control the superheat of evaporator and make the system run stably and safely.

\section{References}

[1] Shieh N C, Liang K Z, Mao C J. Robust Output Tracking Control of an Uncertain Linear System via a Modified Optimal Linear-Quadratic Method[J]. Journal of Optimization Theory \& Applications, 2003, 117(3):649-659.

[2] Wang Qijie. Analysis of heat and mass transfer in convective heat and mass transfer. Xi'an: Xi'an Jiao Tong University press, 1991.

[3] Macarthur J W, Grald E W. Unsteady compressible twophase flow model for predicting cyclic heat pump performance and a comparison with experimental data[J]. International Journal of Refrigeration, 1989, 12(1):29-41.

[4] He X D. Dynamic modeling and multivariable control of vapor compression cycles in air conditioning systems $[\mathrm{M}] / /$ Principles and Practice of Constraint Programming. Springer International Publishing, 1996:590-605.

[5] Zhang Chunlu, Ding Guoliang, Zhao force. New working fluid of refrigeration and air conditioning: calculation methods of thermal physical properties and practical charts[M]. Shanghai Jiao Tong University press, 2003.

[6] Shieh N C, Liang K Z, Mao C J. Robust Output Tracking Control of an Uncertain Linear System via a Modified Optimal Linear-Quadratic Method[J]. Journal of Optimization Theory and Applications, 2003, 117(3):649-659. 